\title{
Identifying cultural, climatic and temporal factors influencing Striga asiatica abundance within rice-maize systems in mid-west Madagascar
}

\author{
Donald Scott ${ }^{1}$, Julie Scholes ${ }^{1}$, Meva Randrianjafizanaka ${ }^{2}$, Patrice Autfray ${ }^{3}$, Jean \\ Randriamampianina ${ }^{4}$, and Rob Freckleton ${ }^{5}$ \\ ${ }^{1}$ The University of Sheffield \\ ${ }^{2}$ University of Antananarivo \\ ${ }^{3}$ CIRAD Languedoc-Roussillon \\ ${ }^{4}$ FOFIFA \\ ${ }^{5}$ University of Sheffield
}

June 24, 2021

\begin{abstract}
The parasitic weed genus Striga causes huge losses to crop production in sub-Saharan Africa, estimated to be in excess of $\$ 7$ billion per year, affecting subsistence farmers who frequently lack access to novel technologies proposed for control. Effective Striga management therefore requires the development of strategies utilising existing cultural and management practices. We report a multi-year, landscape-scale monitoring project for Striga asiatica in the mid-west of Madagascar, undertaken over 2019-2020 with the aims of examining cultural, climatic and edaphic factors currently driving abundance and distribution. Long-distance transects were established across the middle-west region of Madagascar, over which Striga asiatica abundance in fields was estimated. Analysis of the data highlights the importance of crop variety and legumes in driving Striga density. Moreover, the dataset revealed significant effect of precipitation seasonality, mean temperature and altitude in determining abundance. A composite management index indicated the effect of a range of cultural practices on changes in Striga abundance. The findings support the assertion that single measures are not sufficient for the effective, long-term management of Striga. Furthermore, the composite score has potential as a significant guide of ISM control beyond the geographic range of this study.
\end{abstract}

\section{Hosted file}

Identifying cultural, climatic and temporal factors influencing Striga asiatica abundance within rice-available at https://authorea.com/users/421679/articles/527612-identifying-culturalclimatic-and-temporal-factors-influencing-striga-asiatica-abundance-within-rice-maizesystems-in-mid-west-madagascar 